\title{
Problem-solving performance with task overload: Effects of self-pacing and trait anxiety
}

\author{
RICHARD E. MAYER \\ University of California, Santa Barbara, California 93106
}

\begin{abstract}
Ninety-two subjects solved a series of problems without enough time to finish and worked either at a pace and in an order determined by the experimenter (experimenter-paced) or at their own pace and order under self-administered time deadlines (self-paced). Self-pacing resulted in superior performance on rote and poorer performance on cognitive problems relative to experimenter-paced groups. Self-pacing had no effect on low-anxious subjects but increased performance for high-anxious subjects, and high-anxious subjects performed better on rote and poorer on cognitive problems relative to low-anxious subjects. Practical and theoretical implications were discussed.
\end{abstract}

In solving a set of problems without enough time to finish (i.e., task overload), performance may be influenced by whether subjects work on each problem in an order and for a time period completely controlled by the experimenter (E-paced) or at their own pace and order with self-administered time deadlines (S-paced). Three important questions, suggested by careful reviews of the related literature (Atkinson \& Raynor, 1974; Levitt, 1967) are: (1) Does self-pacing produce different effects for different types of problem taskswhat is performed best under self-pacing? This question is informed by the interaction between pacing and task, such as the classic finding that stress has a negative effect on complex or difficult responses relative to easier or simpler responses (Eriksen \& Wechsler, 1955; Patrick, 1934). (2) Does self-pacing have different effects for subjects with different levels of trait anxietywho performs best under self-pacing? This question is informed by the interaction between pacing and anxiety, such as the typical finding that high-anxious subjects tend to work more poorly under time pressure relative to low-anxious subjects (Morris \& Liebert, 1969; Siegman, 1956). (3) Does the subject's level of trait anxiety have different effects for different problem tasks-who performs what best? This question is informed by the interaction between anxiety and task, such as the typical finding that anxiety has a negative effect on complex or difficult tasks relative to simpler or easier ones (Harleston, 1962; Korchin \& Levine,

This research was conducted at the Human Performance Center, University of Michigan, supported by the Office of the Advanced Research Projects Agency under Order 1949, and monitored by the Air Force Office of Scientific Research under Contract F44620-72-C-0019. I appreciate the assistance of Robert Bjork, Richard Pew, and Daniel Weintraub. The comments of John Atkinson on an earlier draft are also appreciated. Requests for reprints should be sent to: Richard Mayer, Department of Psychology, University of California, Santa Barbara, California 93106.
1957; Montague, 1953). The present study attempted to increase the generalizability of existing findings with respect to these interactions by examining more complicated problem tasks than the traditionally used tasks of discrimination performance, list learning, and anagrams; by using a motivational manipulation (i.e., self-pacing) that more closely approximates the circumstances of the overburdened worker; and by using a more recent measure of anxiety rather than the traditionally used Manifest Anxiety Scale (Taylor, 1953) and Test Anxiety Questionnaire (Mandler \& Sarason, 1952).

\section{EXPERIMENT 1}

\section{Method}

Subjects and design. Twenty subjects were recruited from the Human Performance Center subject pool and were paid \$2 for the 1-h session. Half the subjects received the S-paced treatment and half did not (E-paced), but all subjects attempted to solve the same series of cognitive and rote problems.

Materials. Eight problem tasks, seven of which were adapted from French's (1963) Kit for Cognitive Reference, were typed on separate sheets of paper. Four tasks were considered to be clerical or "rote": (1) target search for all the letter "a's" in a 600 -word passage, (2) identity judgments for 100 pairs of numbers, (3) 100 multiplication and subtraction problems with two-digit numbers, and (4) 60 division and addition problems with two- and three-digit numbers. Four tasks were considered to be general reasoning or "cognitive": (1) 64 figural concept-formation items, (2) 15 oddity problems, (3) 32 twoterm deductions (from Baddeley, 1968), and (4) 15 three-term deductions. In addition, a wooden rack with eight slots, a large electric timer, and a stopwatch were used.

Procedure. Subjects were randomly assigned to treatment groups (either S- or E-paced) and run individually. For the Spaced condition, each subject was introduced to all eight tasks, told he would have a total of $25 \mathrm{~min}$ to work on them as indicated by the timing clock, told he could proceed in any order and return to unfinished tasks, and was allowed to work a maximum of $3 \mathrm{~min}$ on each problem. For the E-paced group, the problems were presented in an order determined by the experimenter (randomized by a Latin square); after $3 \mathrm{~min}$ of work on the first problem, that problem was over and the next problem was worked on for $3 \mathrm{~min}$, and so on. 
Table 1

Proportion Correct Response for Two Pacing Groups by Type of Problems: Experiment 1

\begin{tabular}{ccc}
\hline & \multicolumn{2}{c}{ Type of Task } \\
\cline { 2 - 3 } Pacing Treatment & Rote & Cognitive \\
\hline Self-Paced (Overload) & .56 & .59 \\
Experimenter-Paced & .49 & .66 \\
\hline
\end{tabular}

\section{Results}

The proportion of correct responses by type of task for the two treatment groups, shown in Table 1, was obtained by averaging the number correct divided by the total possible for each of the four tasks of each type. Although an analysis of variance revealed no overall effect due to pacing $[F(1,32)=1.00, p=n . s$.$] , there$ was a significant two-way interaction of Pacing by Problem Type $[F(1,22)=5.67, p<.05]$, with S-paced subjects performing better on rote and worse on cognitive tasks relative to E-paced subjects.

\section{EXPERIMENT 2}

Experiment 2 examined the second question.

\section{Method}

Subjects and design. Twenty-four paid subjects were recruited from a pool of University of Michigan students who had previously taken the State-Trait Anxiety Inventory (STAI) (Spielberger \& Gorsuch, 1966). A 2 by 2 between-subjects design was used, with the factors being anxiety (high vs low score on the STAI) and pacing (self- vs experimenter-pacing).

Materials. Eight problem tasks, adapted from traditional one-answer problem-solving puzzles, were typed on separate sheets of paper. The tasks were to generate a $4 \times 4$ Latin square, to arrange a $3 \times 3$ magic square (from Schuh, 1968), to solve a complex anagram (from Tresselt \& Mayzner, 1966), to connect nine dots with four consecutive lines (from Schuh, 1968), a Katona (1940) card trick, a Katona (1940) matchstick problem, a variation of the Luchins (1942) water jar problem, and a geometric puzzle (from Schuh, 1968). In addition to the other materials used in Experiment 1, there were eight loud-ticking chess clocks arranged on tiers for each of the eight problems.

Procedure. Subjects who scored below 15 (out of 66) or above 25 on the trait anxiety scale of the STAI were randomly assigned to treatments, and run individually. The same procedure was used as in Experiment 1 except that all subjects were in structed they would receive a bonus for good performance, and a 10-min limit was imposed on each task; for S-paced subjects, there was a 50-min overall limit indicated on the large timing clock, and there were individual 10-min-limit clocks for each problem which subjects started when working on the problem and stopped when changing to another.

\section{Results}

Proportion correct solutions and average solution time for the eight items (unsolved items were assigned a solution time of $600 \mathrm{sec}$ ) are shown in Table 2 for the four groups. An analysis of variance revealed that S-paced subjects solved significantly more problems than the E-paced group $[F(1,20)=14.35, p<.005]$ and high-anxious subjects solved significantly more problems than the low-anxious group $[\mathrm{F}(1,20)=5.29, \mathrm{p}<.05]$. A significant Anxiety by Pacing interaction $[F(1,20)=$ $7.35, \mathrm{p}<.025]$ is reflected in the observation that self-pacing had no effect on low-anxious subjects but greatly improved performance for high-anxious subjects. The results with respect to solution times closely shadow these findings; however, only the main effect of stress reached a statistically reliable level $[F(1,20)=5.72$, $\mathrm{p}<.05$ ] .

An analysis of the distribution of solutions over the solution period shows that the S-paced/high-anxious subjects performed relatively well during the latter half of the period, on problems rated most difficult by the other groups. For example, proportion correct at the halfway point were: S-paced/high anxiety, .56; S-paced/low anxiety, .56; E-paced/high anxiety, .38; E-paced/low anxiety, .38 .

\section{Supplemental Study}

In order to replicate the surprising finding that high anxiety was an asset in stressful problem-solving situations, four new subjects scoring low in anxiety were matched for Mathematics SAT score with four new subjects scoring high in anxiety, and were given the self-pacing treatment described in Experiment 2. As in Experiment 2, high-anxious/S-paced subjects averaged $85 \%$ correct solutions and $311 \mathrm{sec} /$ solution, while lowanxious/S-paced subjects averaged $56 \%$ correct and $396 \mathrm{sec} /$ solution $(\mathrm{t}=3.86, \mathrm{df}=6, \mathrm{p}<.01$, for proportion correct; $t=1.44, d f=6, p=n . s$. , for solution time).

\section{EXPERIMENT 3}

Experiment 3 examined the third question and attempted to replicate and extend the findings of a Pacing by Task interaction in Experiment 1 and Pacing by Anxiety interaction in Experiment 2.

\section{Method}

Subjects and design. Forty paid subjects who had previously taken the STAI were recruited from the Human Performance Center subject pool. A 2 by 2 factorial design was used for between-subjects factors, namely pacing (self- vs experimenterpacing) and anxiety (high vs low anxiety); since all subjects received the same problems, type of problem (rote vs cognitive) served as a within-subjects factor.

Materials. Eight problems-each having a single criterion for

Table 2

Proportion Correct Response and Average Time Per Solution for Two Pacing Groups by Anxiety Level: Experiment 2

\begin{tabular}{|c|c|c|c|c|}
\hline \multirow[b]{3}{*}{ Pacing Treatment } & \multirow{2}{*}{\multicolumn{2}{|c|}{$\begin{array}{c}\begin{array}{c}\text { Proportion } \\
\text { Correct }\end{array} \\
\text { Level of Anxiety }\end{array}$}} & \multirow{2}{*}{\multicolumn{2}{|c|}{$\begin{array}{c}\begin{array}{c}\text { Average Time } \\
(\mathrm{Sec})\end{array} \\
\text { Level of Anxiety }\end{array}$}} \\
\hline & & & & \\
\hline & Low & High & Low & High \\
\hline $\begin{array}{l}\text { Self-Paced (Overload) } \\
\text { Experimenter-Paced }\end{array}$ & $\begin{array}{l}.69 \\
.67\end{array}$ & $\begin{array}{l}.94 \\
.65\end{array}$ & $\begin{array}{l}334 \\
363\end{array}$ & $\begin{array}{l}277 \\
382\end{array}$ \\
\hline
\end{tabular}


completion, as in Experiment 2, rather than a series of short items, as in Experiment 1-were typed on separate sheets of paper. Four of the problems were adapted from the rote problems of Experiment 1: (1) target search for 80 letter "a's," (2) identity judgments for 40 mismatched number pairs, (3) chain of multiplications and subtractions totaling one number, and (4) chain of divisions and additions totaling one number. The four cognitive problems were the same as those used in Experiment 2: (1) anagram, (2) water jar, (3) card trick, (4) matchstick. The same clocks and holders were used as in Experiment 2, and a preexperimental questionnaire was constructed.

Procedure. Subjects were randomly assigned, except for the constraint of matching groups for average SAT-M score, and run individually. The $S$ - and E-paced conditions were the same as in Experiment 2, including the $10-\mathrm{min} /$ problem time limits.

\section{Results}

Data for solution times and proportion correct response were recorded and analyzed as in Experiment 2, and are shown in Table 3 . An analysis of the results with respect to solution times revealed: (1) a superiority of S-paced subjects over E-paced subjects $[F(1,32)=3.00, p<.10]$ and low-anxiety subjects over high-anxiety subjects $[\mathrm{F}(1,32)=15.78, \mathrm{p}<.001]$; (2) the same pattern of Pacing by Task interaction as in Experiment 1, with the S-paced group performing better on rote and slightly worse on cognitive problems relative to E-paced subjects $[F(1,32)=5.64, p<.025]$ (3) the same pattern of Pacing by Anxiety interaction as in Experiment 2, with self-pacing having no effect on the average solution time of low-anxious subjects but having a positive effect for high-anxious subjects $[F(1,32)=2.96, p<.10] ;(4)$ a pattern of Anxiety by Task interaction in which high- and low-anxious subjects performed at about the same rate for rote problems but the high-anxious group performed much worse relative to the low-anxious group on cognitive problems $[F(1,32)=14.13, p<.001]$.

The results with respect to proportion correct response show the same general patterns as above; however, only the Anxiety by Task Type interaction reached statistically reliable levels $[\mathrm{F}(1,32)=15.78, \mathrm{p}<.001]$. There was no evidence, in any case, of a three-way interaction of Pacing by Anxiety by Task Type $(F<1)$ for time and proportion correct.

Table 3

Proportion Correct Response and Average Time Per Solution for Four Pacing by Anxiety Groups by Type of Task: Experiment 3

\begin{tabular}{|c|c|c|c|c|}
\hline \multirow[b]{2}{*}{ Pacing by Anxiety Group } & \multicolumn{2}{|c|}{$\begin{array}{c}\text { Proportion } \\
\text { Correct }\end{array}$} & \multicolumn{2}{|c|}{$\begin{array}{l}\text { Average Time } \\
\text { (Sec) }\end{array}$} \\
\hline & $\begin{array}{l}\text { Rote } \\
\text { Task }\end{array}$ & $\begin{array}{c}\text { Cogni- } \\
\text { tive } \\
\text { Task }\end{array}$ & $\begin{array}{l}\text { Rote } \\
\text { Task }\end{array}$ & $\begin{array}{c}\text { Cogni- } \\
\text { tive } \\
\text { Task }\end{array}$ \\
\hline $\begin{array}{l}\text { S-Paced/High Anx (Overload) } \\
\text { S-Paced/Low Anx (Overload) } \\
\text { E-Paced/High Anx } \\
\text { E-Paced/Low Anx }\end{array}$ & $\begin{array}{l}.95 \\
.91 \\
.80 \\
.77\end{array}$ & $\begin{array}{l}.52 \\
.75 \\
.40 \\
.82\end{array}$ & $\begin{array}{l}388 \\
419 \\
486 \\
455\end{array}$ & $\begin{array}{l}438 \\
354 \\
465 \\
316\end{array}$ \\
\hline
\end{tabular}

As in Experiment 2, an analysis of the distribution of solutions over the total solution period shows that, relative to E-paced/high-anxious groups, the S-paced/ high-anxious subjects performed particularly well during the latter half of the solution period, especially on more difficult "cognitive" problems. For example, proportion correct at the halfway point were: S-paced/high anxiety, .40; S-paced/low anxiety, .38; E-paced/high anxiety, $.31 ;$ E-paced/low anxiety, .31 .

\section{DISCUSSION}

The Pacing by Task interaction (Experiments 1 and 3) and the Anxiety by Task interaction (Experiment 3) help extend traditional findings to a new area. In addition, these findings are only partially consistent both with Spence's (1960) "drive level" view-that stress energizes well-learned responses more than complex responses-and with Sarason's (Sarason, Davidson, Lighthall, Waite, \& Ruebush, 1960) "situational reaction" view-that subjects learn situational reactions to stress which may interfere more with complex performance than with welllearned performance. The most surprising finding, represented by the Pacing by Anxiety interaction (Experiments 2 and 3), is most consistent with Sarason's "situational reaction" concept; apparently, high-anxious subjects may begin by reacting to self-pacing in task-irrelevant ways but eventually react by maintaining momentum as the session continues.

\section{REFERENCES}

Atxinson, J., \& Raynor, J. Motivation and achievement. Washington: Winston, 1974.

BADDELEY, A. D. A 3-min reasoning test based on grammatical transformation. Psychonomic Science, 1968, 10, 341-342.

ERIKSEN, C. W., \& WEChSLER, H. Some effects of experimentally induced anxiety upon discrimination behavior. Journal of Abnormal and Social Psychology, 1955, 51, 458-463.

FRENCH, J. W. Kit of reference tests for cognitive factors. Princeton, N.J: Educational Testing Service, 1963.

Harleston, B. W. Test anxiety and performance in problem solving situations. Journal of Personality, 1962, 30, 557-573.

Katona, G. Organizing and memorizing. New York: Columbia University Press, 1940.

Korchin, S. J., \& Levine, S. Anxiety and verbal learning. Journal of Abnormal and Social Psychology, 1957, 54, 234-240.

LevitT, E. E. The psychology of anxiety. Indianapolis: Bobbs-Merrill, 1967.

LuchINs, A. S. Mechanization in problem solving: The effect of einstellung. Psychological Monographs, 1942, 54 Whole No. 248.

Mandler, G., \& Sarason, S. B. A study of anxiety and learning. Journal of Abnormal and Social Psychology, 1952, 47, 166-173.

Montague, E. K. The role of anxiety in serial rote learning. Journal of Experimental Psychology, 1953, 23, 91-95.

MORRIS, L., \& LIEBERT, R. Effects of anxiety on timed and untimed intelligence tests. Journal of Consulting and Clinical Psychology, 1969, 33, 240-244.

Patrick, J. R. Studies in rational behavior and emotional excitement: II. The effect of emotional excitement on rational behavior in human subjects. Journal of Comparative Psychology, 1934, 18, 153-195.

Sarason, S. B., Davidson, K. S., Lightball, F. F., Waite, 
R. R., \& Ruebush, B. K. Anxiety and elementary school children. New York: Wiley, 1960.

Scнuн, F. The master book of mathematical recreations. New York: Dover, 1968.

Siegman, A. W. The effect of manifest anxiety on a concept formation task, a nondirected learning task, and on timed and untimed intelligence tests. Journal of Consulting Psychology, 1956, 20, 176-178.

SPENCE, K. W. Behavior theory and learning. Englewood Cliffs, N.J: Prentice-Hall, 1960.

SPIElberger, C. D., \& GorsuCh, R. L. Mediating processes in verbal conditioning. Vanderbilt University Technical Report, 1966.

TAYLOR, J. A. A personality scale of manifest anxiety. Journal of Abnormal and Social Psychology, 1953, 48, 285-290.

Tresselt, M. E., \& MAYZnER, M. S. Normative solution times for a sample of 134 solution words and 378 associated anagrams. Psychonomic Monograph Supplement No. 15, 1966, 1, 293-298.

(Received for publication November 22, 1976.) 